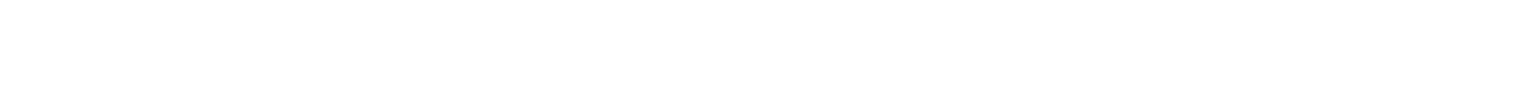 وأوزلن نكور الأرلب المحلية
}

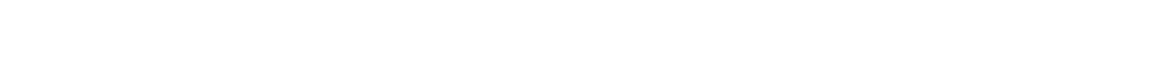 \\ قمم علوم الحية \\ كلية العلوم \\ جلمعة الموصل
}

(تاريخ الإستلام 26/ 10 /2011 ؛ تاريخ القبول 26 /3 / 2012)

\section{المالخص}

صممت هذه الدرلسة لمعرفة تأثير الكوليسترول بتركيز 260ملغم/كغم عليقة والمستخلص المغلي للفلفل

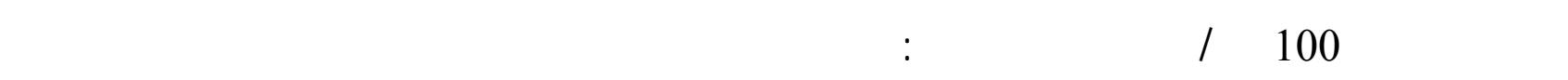

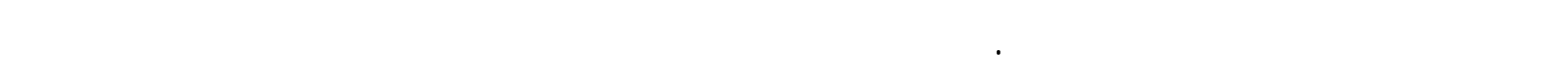
4 و8 أسابيع من بدو المعلملة.

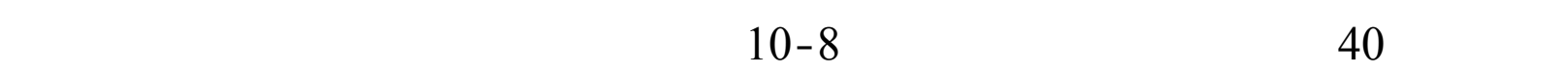

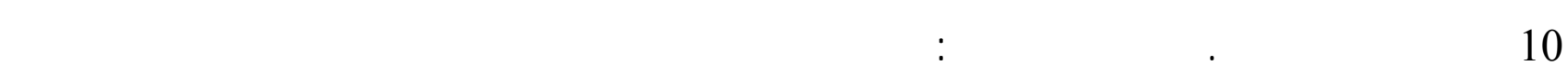

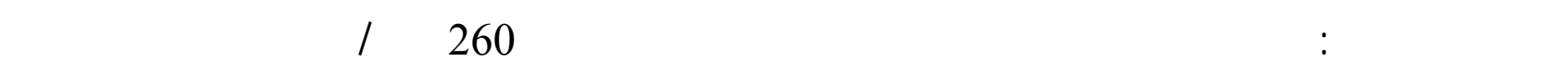

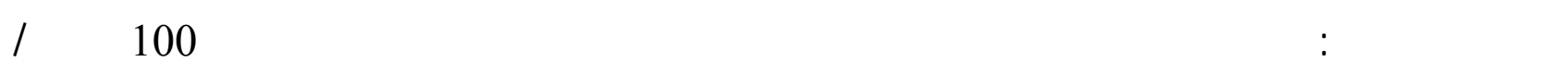

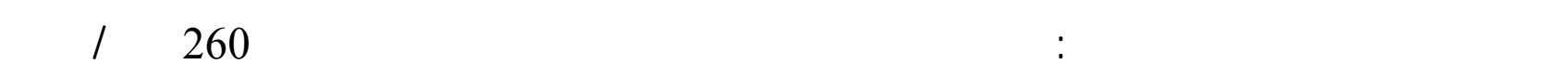

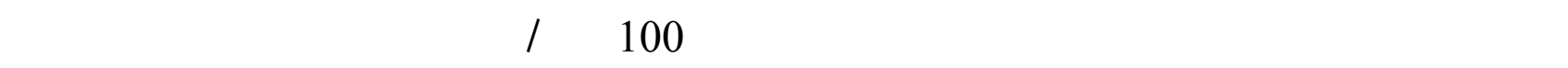

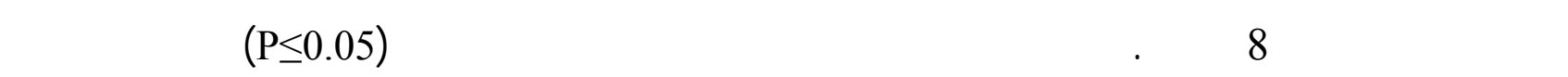

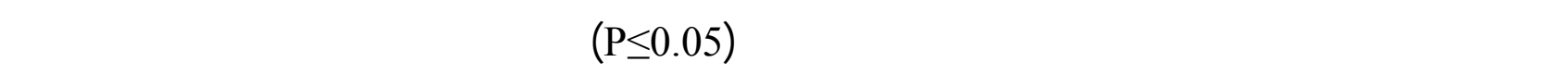

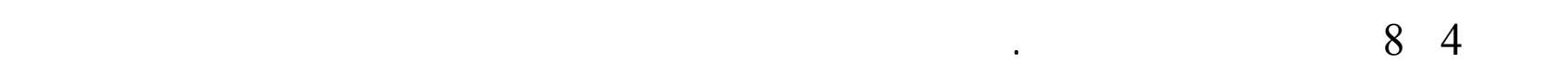

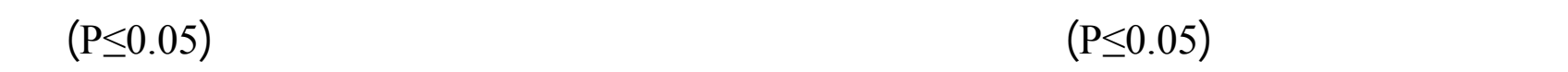

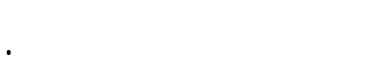

الكاملت الدالة: المستخلص المغلي لفلفل الاحمر، وزن الجم، الكوليسترول، الهرمونت، الأرافب. 
هدل طارقسعدون الشملش ومنتهى محمود داؤد التطان

\title{
Effect of Cholesterol and Boiled Extract of Red Pepper on the Level of some Hormones and Weights of Local Male Rabbits
}

\author{
Muntaha M. Al-Kattan Hadeel T. Al-Ishlash \\ Department of Biology \\ College of Science \\ University of Mosul
}

\begin{abstract}
The current study was designed to investigate the effect of cholesterol supplementation at a dose of $(260 \mathrm{mg} / \mathrm{kg}$ ration) and boiled extract of red pepper at a dose of $(100 \mathrm{mg} / \mathrm{kg}$ body weight) on the Testosterone hormone, Thyroid stimulating hormone or Thyrotropin, thyroxine, thyronine, and it is effects on the body weights of male rabbits after 4,8 weeks of the start of treatment.

Forty local male rabbits aged (8-10) months old were randomly divided into four groups (10 animals/group) to be treated as follows:

First group: Standard ration and distilled water represented as control groups.

Second group: Standard ration plus cholesterol at the dose $(260 \mathrm{mg} / \mathrm{kg}$ ration $)$ and distilled water.

Third group: Standard ration with drinking red pepper fruit boiled extract at the dose $(100 \mathrm{mg} / \mathrm{kg}$ body weight).

Fourth group: Standard ration plus cholesterol $(260 \mathrm{mg} / \mathrm{kg}$ ration) in addition to drinking red pepper fruits boiled extract at a dose of ( $100 \mathrm{mg} / \mathrm{kg}$ body weight).

All groups were treated daily for eight weeks.

Results showed that cholesterol treatment caused significant decrease $(\mathrm{P} \leq 0.05)$ in the hormones level, with a significant increase $(\mathrm{P} \leq 0.05)$ on the body weights of treated rabbit after 4 and 8 weeks. Furthermore, treatment with red pepper boiled extract led to a significant increase $(\mathrm{P} \leq 0.05)$ on the levels of the studied hormones, and a significant decrease $(\mathrm{P} \leq 0.05)$ in the body weights of treated rabbits.
\end{abstract}

Keywords: Red Pepper boiled extract, Body weight, Cholesterol, Hormones, Rabbits.

\section{الفقمة}

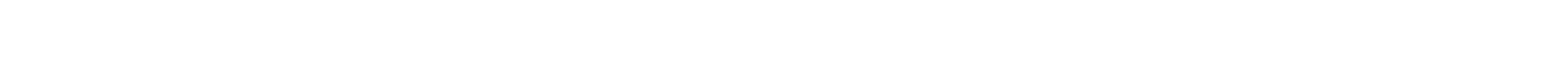

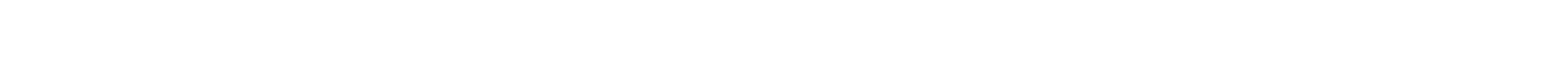

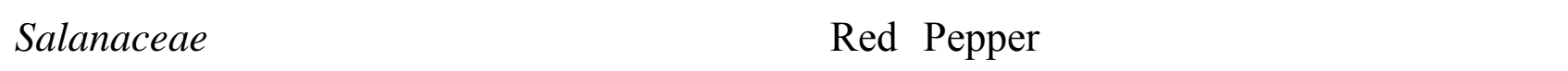

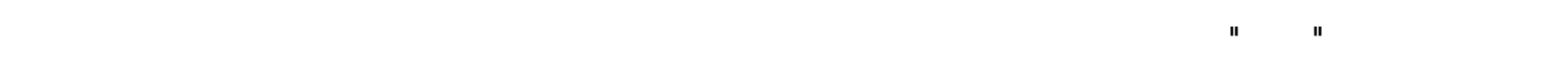
(Ahuja et al., 2006) (القتعود القيمة الغذائية العالية لثمار الفلفل الأحمر إلى لحتوائه على كميلت كبيرة من فيتلمين C. إذ أن كل 100 غم من مسحوق ثمرة الفلف الأحمر يحتوي على 175 ملغم من هـ ذا الفيت لمين 
إضلفة إلى 1.2 غم بروتين، 11 ملغم كللسيوم، 0.06 ملغم من الثايمن، 0.30 ملغ م مـ ـن الرايب -وفلافن،

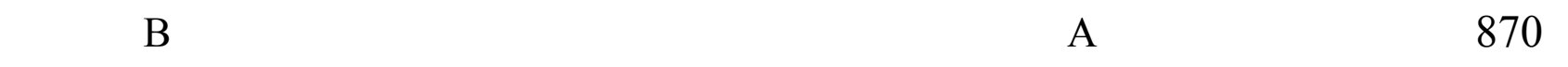
لحتوائه على مستوى عل من المادة الفعالة الكبسلسين (MacGvillivary, 1961) . كما أن الحرارة المتولة

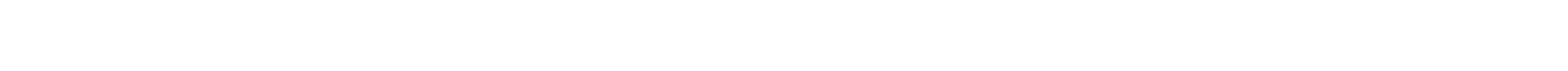

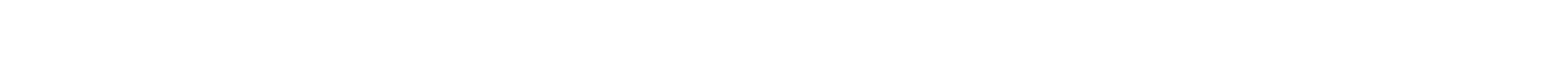

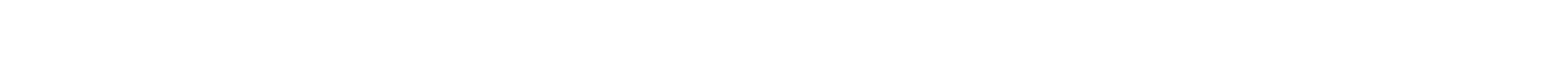

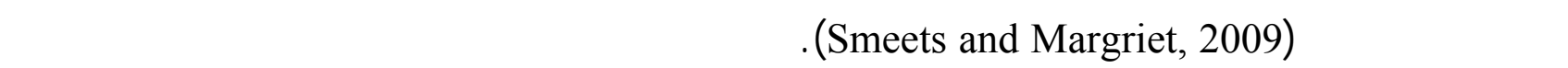

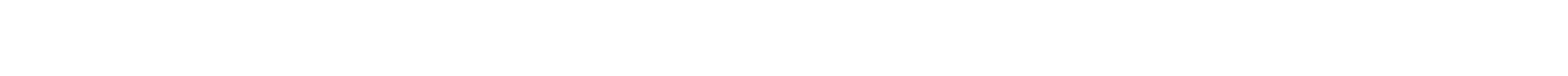

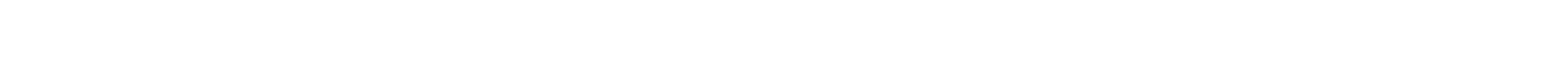

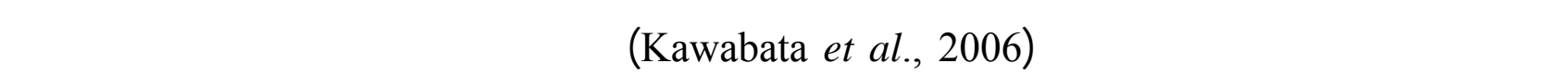

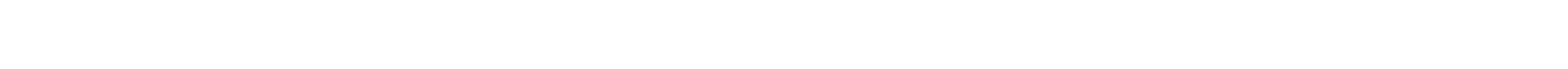

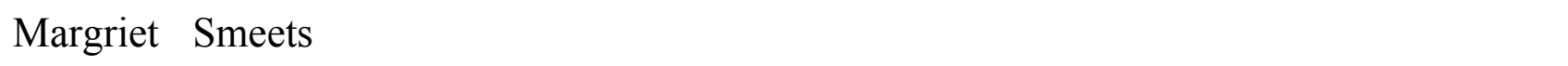

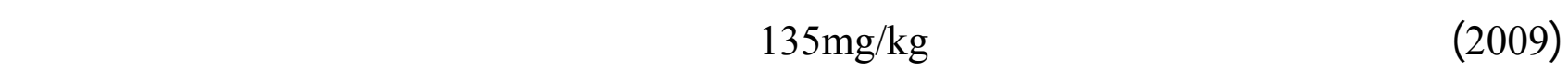

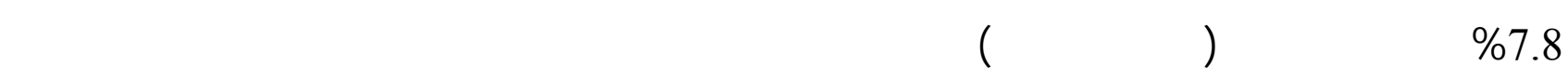

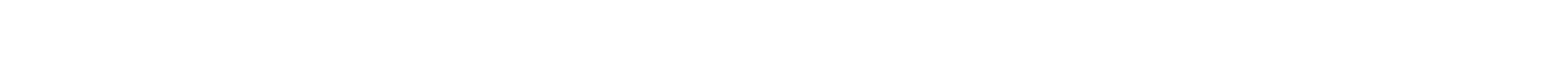

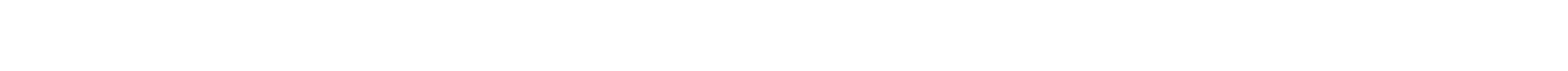

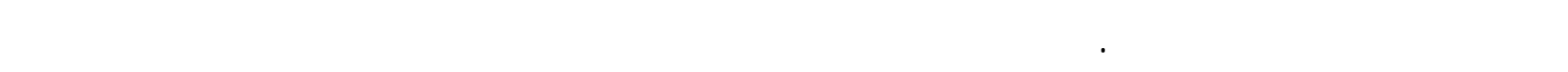

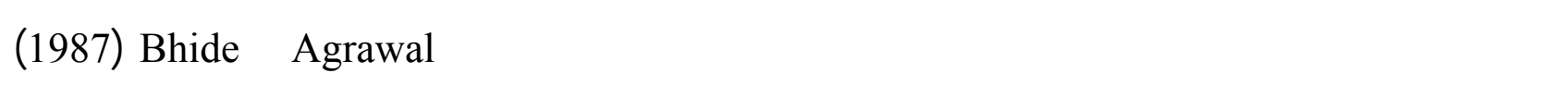

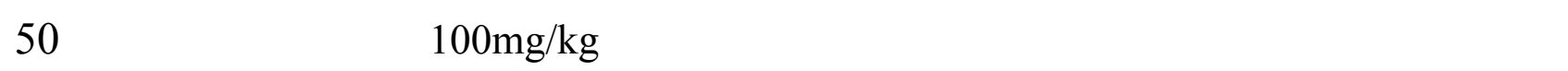

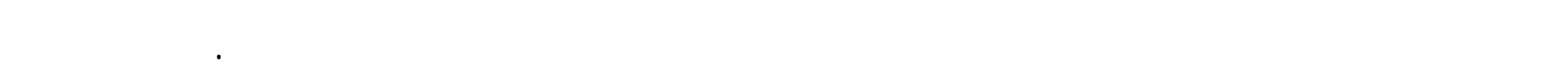

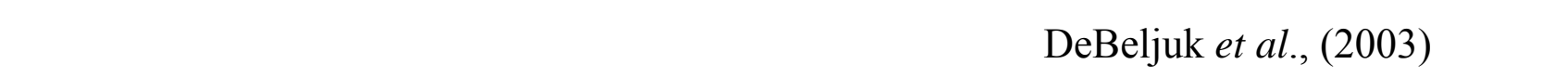

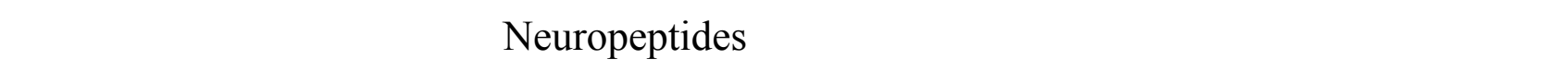

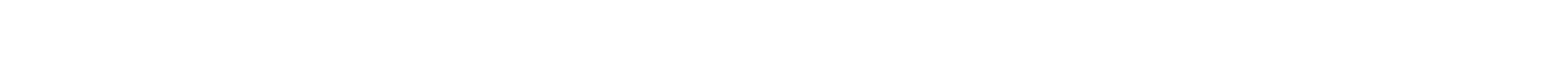

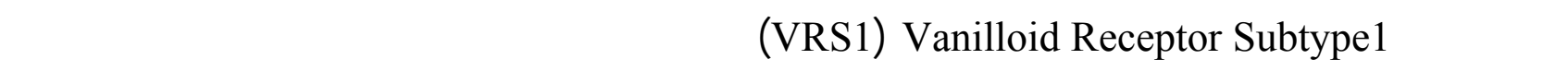
وأن وجوه عمل على تحريض عملية تكوين الظف Spermatogenesis وزيادة أع دادها ون شططها بآلي تحفيز هذا الناقل بالمادة الأسلس التي يعل عليهل عليها ألا وهي الكبسلسن المكون اللاذع للفلفل الأحمر ( Erdost 
الهفف من البهث:

هذت الدرلسة إلى معرفة تأثير الكولسترول بتركيز 260ملغم/كغم عليقة والمستخلص المغلي للفلف لـ الأحمر بجرعة 00 الملغم/كغم وزن هادم على: 1. نشط ومستوى هرمونات التيستوستيرون الذكري، الهرمون المحفز للغ ــة الدرقي ـة، الثايروك سين، الثايرونين.

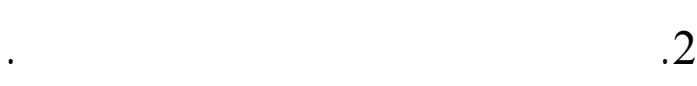

الكبسلسن Capsaicin

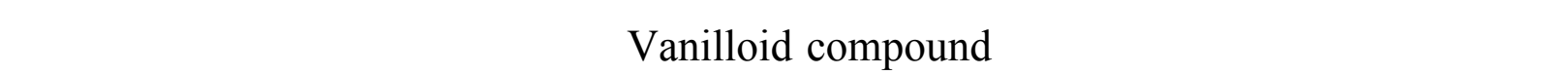

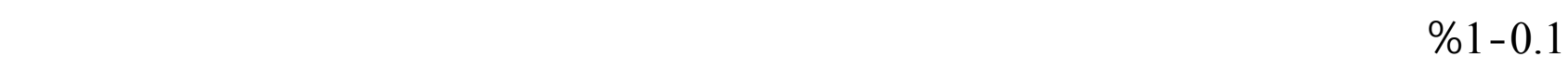
الثمرة (Mathur et al., 2000).

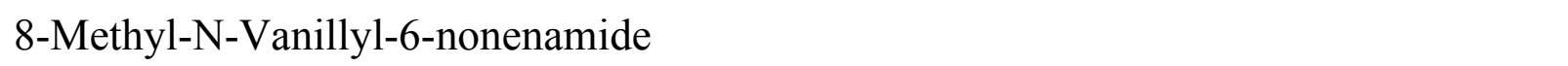

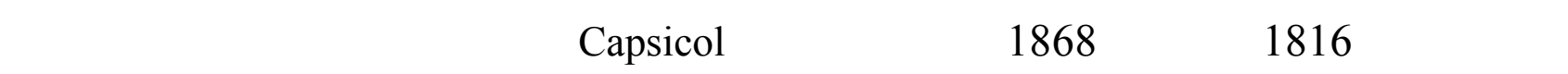

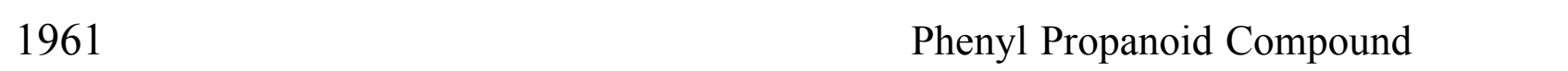
(Flomenbaum et al., 2006)<smiles>CC(C)/C=C/CCCCC(=O)NCc1ccc(O)c(CO)c1</smiles>

الصيغة التركيبية للكبسلين

(Flomenbaum et al.,2006)

\section{المواد وطرائق الهلى}

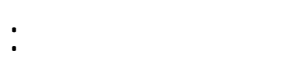

الكولسترط

لمتخدم الكولسترول القي المستخلص من نسبج الكبد، والمصنع منشركة "BDH" البريطاني ة، ت م الحصول عليه من منخر البلم للأدوية والمستلزملت الطبية في محلظة الفينة نينوى. 


\section{تخضير المستخلص المغلي الفلال الأحمر}

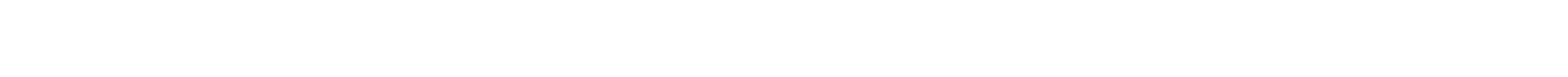

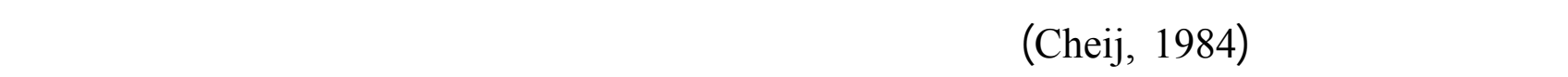
وحفظت في أكيلس ورقية لحن الإستخدلم. وحضر المستخلص المائي المغلي لمسحوق ثمرة الفلفل الأحم ـر

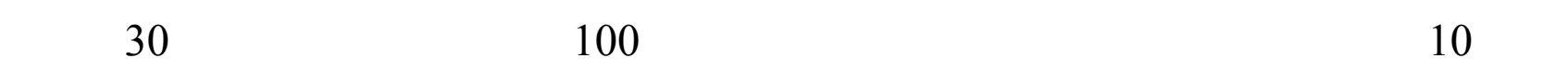

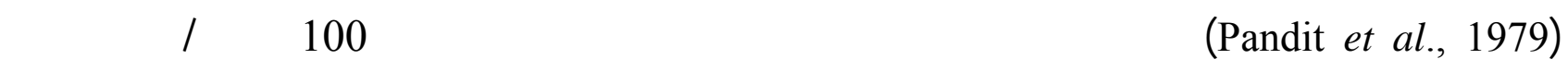

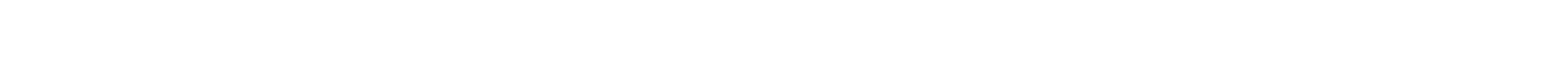

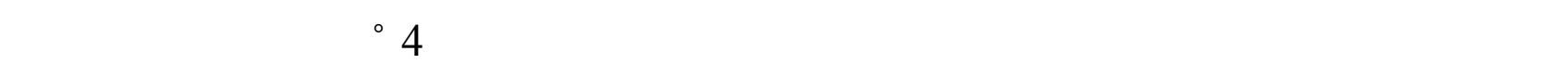
اليوم التالي.

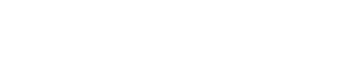

لستخدم في هذه الدرلسة 40 نكرأمن الأرافب المحلية بأعمار تراومت ما بـ بن 8 -10 ألثد هر وأوزان

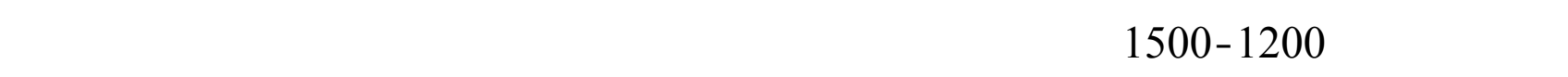

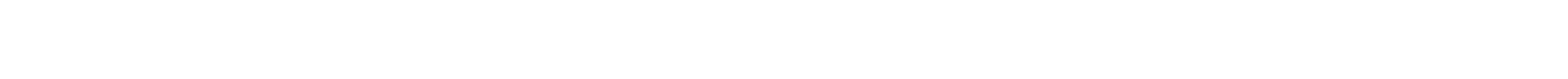

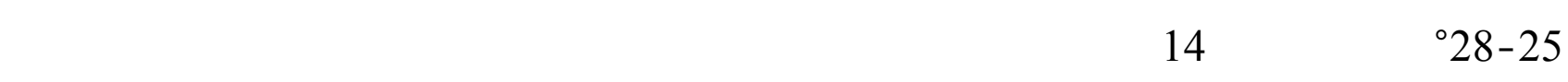

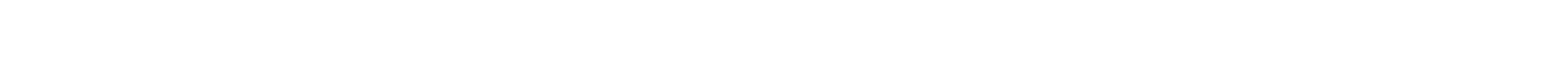

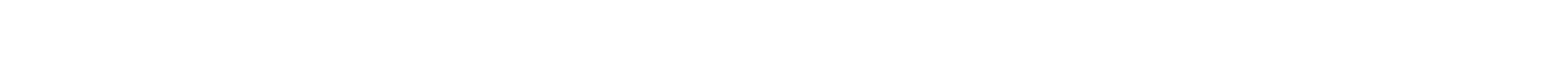
مصنوعة من البلمستيك وثبت بالقفص المنع لنسكلب الماء.

العلقة المستخدة

لستخدت في هذه الدرلسة علقة قيلسية خاصة بالأرافب بنسبة بروتين (6.5 1\%) المقررة م ـن قب لل

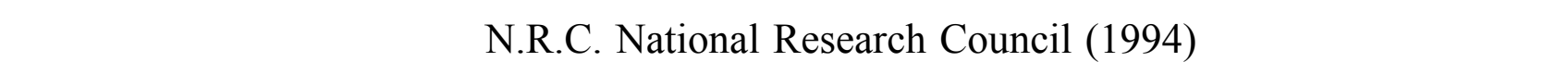

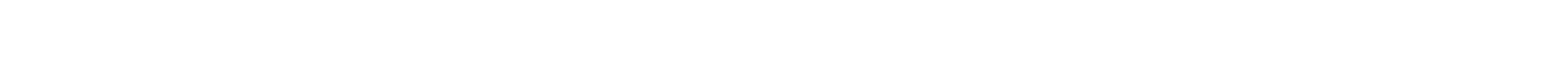
(1978) كما أعطي العلف الأخضر بكميلت متساوية يومياً.

تصميم التجربة

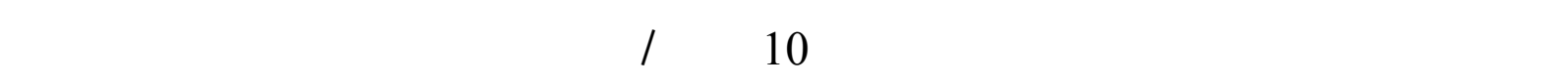

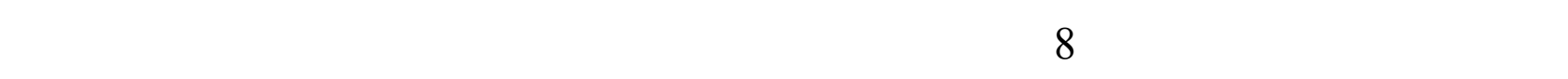

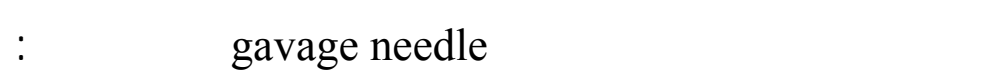
المجموعة الأولل الأط أعطيت عليقة قيلسية وجرعت بالماء المطرر وعدت مجموعة للسيطرة. وكان معدل الـ ـوزن الابت دائي لهذه المجموعة، 1225 غم. 
المجموعة الثلنية

أعليت العليقة المضلف إليها الكولسترول بتركيز 260 ملغم الكغم عليقة (Ameli et al., 1996) وكان معل الوزن الابتدائي لهذه المجموعة، 1225غم. وجرعت الأرافب التابعة للمجموعة الأوله والثانية بالماء المطار عنطريق الفم لمعادلة إجهاد مسك الأرالب (Batchelor and Giddins, 1995).

المجموعة الثالثة

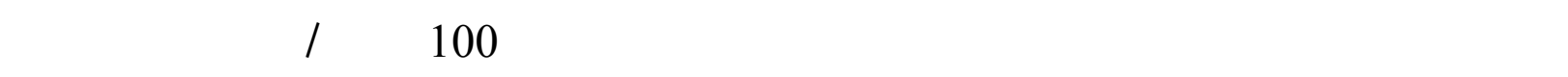
(Kendabie et al., 2007). وكلن معدل الوزن اللبتدائي لهذه المجموعة، 1240 غم.

المجموعة الرلبعة

أعطيت العلقة المضف لها الكولسترول بتركيز 260 ملغم/كغم مع تجريعها بالمستخلص المغلي للفلفل الأحمر وبجرعة 00 الملغم/لكغم وزن هجم. وكلن معل الوزن الابتدائي لهذه المجموعة، 1220 غم.

جمع عينات التمر ونجم

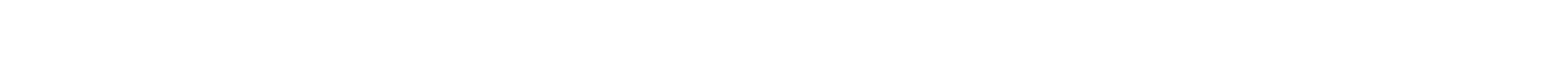

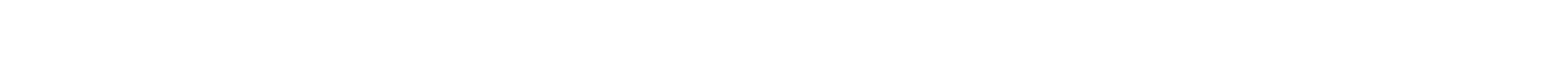

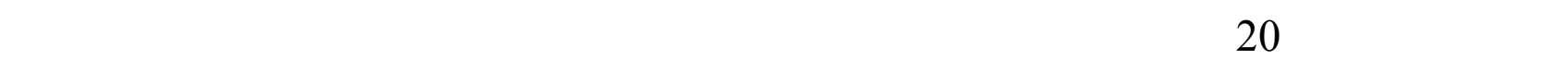

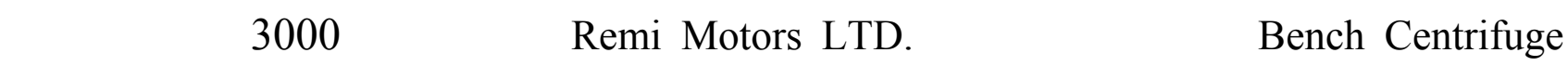
ولمدة 15 دقيقة وحظظ المصل بالتجميد عند درجة -20مْ لحين إجراء الفحوصل الهرمونية. الفحوصل الهرومنية

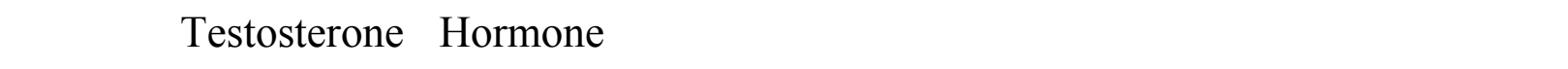

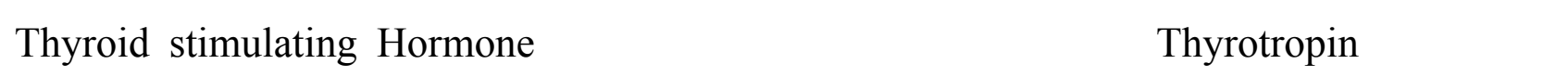
"Thyroxine "T4" هربمون الثايرونين "Th.S.H"

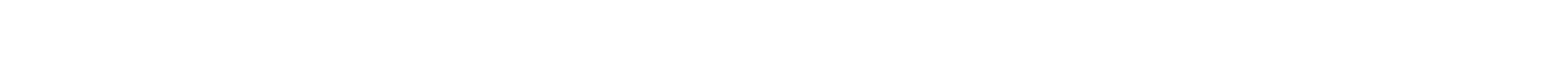

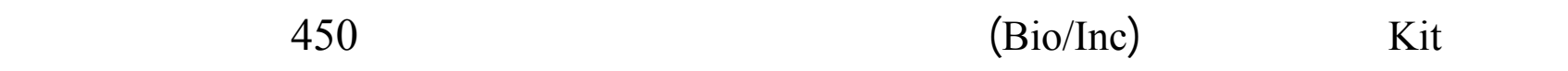
15 دققة بلستخدل جهاز الإليزا المصنع من قبلشركة (Organon, Teknika) الإسترالية.

تسجل الأوزلن

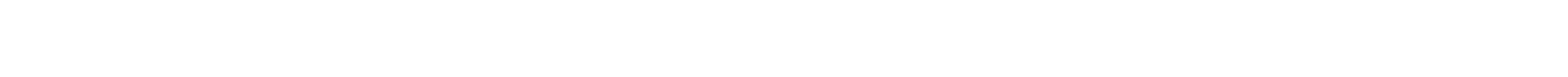

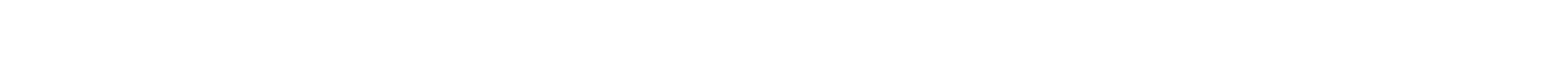
ثمانية أسابيع من بدء المعلملة (يوم النح) . 


\section{الحلالل الإحصائي}

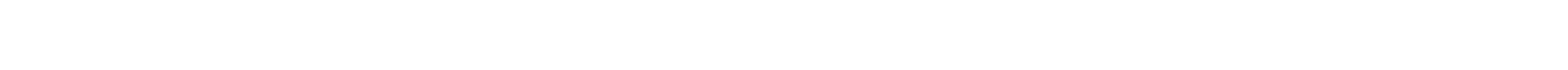

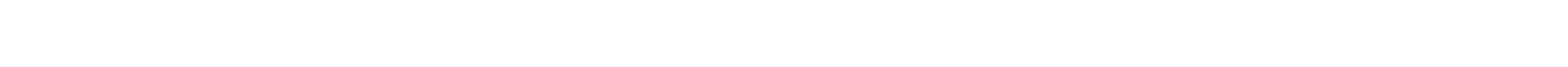

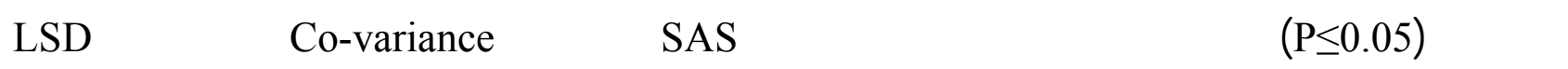
(عنتر، 2010).

\section{النتائج والمنلثة \\ تأثير الكولسترط والفلل الأحمرفي طستوى الهرومنت}

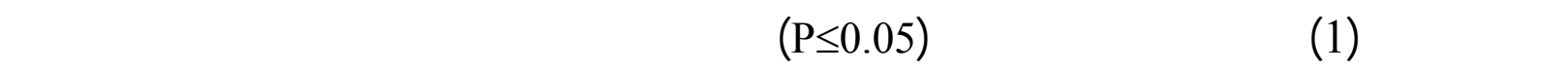

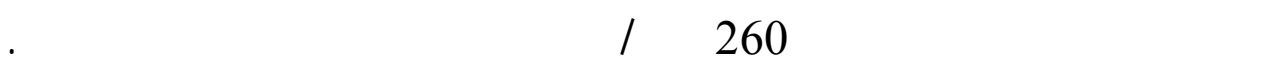

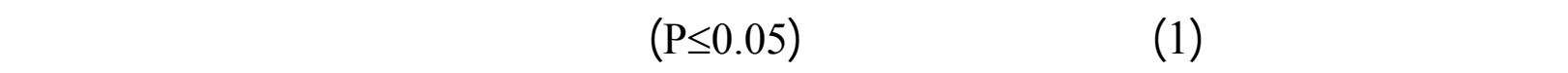

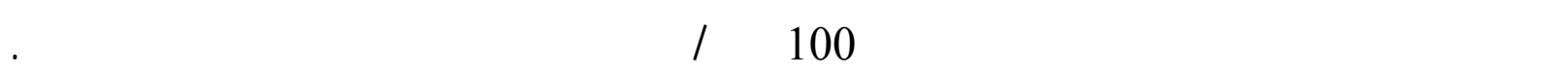

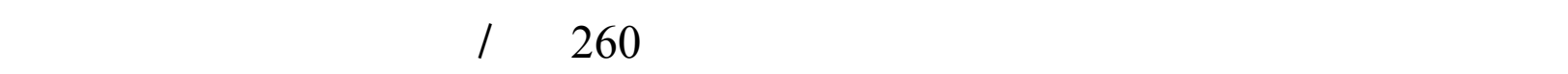

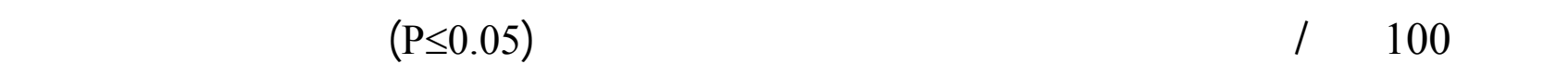

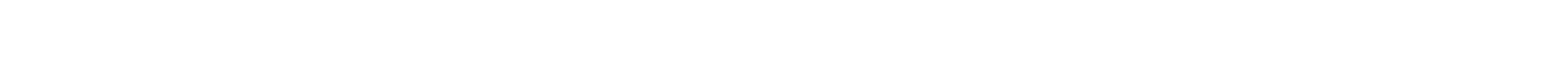

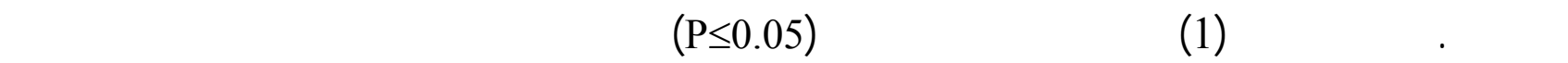
T.S.H

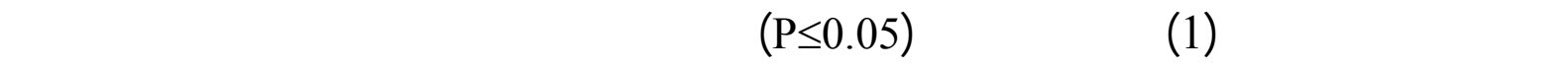
T.S.H

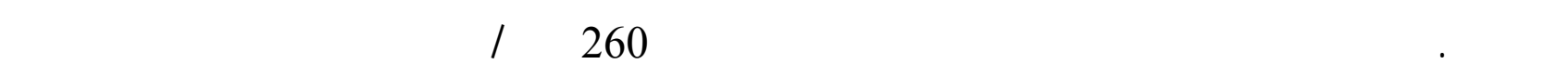

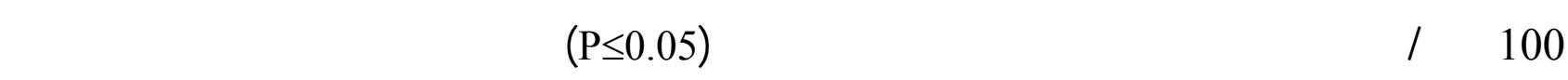
الدرقية مقارنة مع مجموعة الكولسترول لوحله، ووصول القيم إلى قيم مجموعة اللسطرة. 
هيل طارقسعدون الاشلش ومنتهن محمود داؤد التطلن

الجطل 1: تأثير الكولسترط والفلل الأحمرفي مستوى بهض الهرومنلت المدروسة في مطل مم نك ـور

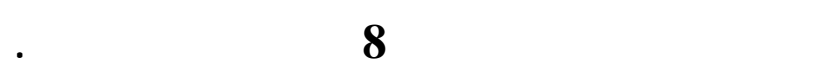

\begin{tabular}{|c|c|c|c|c|c|}
\hline 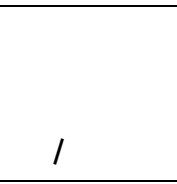 & هزمهن الثليروكسين & اللغهون المرقية المجفز & النستوسنيرهن & المعالات & المجامبع \\
\hline $\begin{array}{c}1.08 \pm 0.07 \\
\mathrm{~B}\end{array}$ & $\begin{array}{c}10.31 \pm 0.07 \\
\mathrm{C}\end{array}$ & $\begin{array}{c}0.60 \pm 0.02 \\
\mathrm{~B}\end{array}$ & $\begin{array}{c}0.29 \pm 0.01 \\
\mathrm{C}\end{array}$ & ماء مقطر وعليقة قيلسية & 1 \\
\hline $\begin{array}{c}0.90 \pm 0.03 \\
\mathrm{C}\end{array}$ & $\begin{array}{c}10.13 \pm 0.02 \\
\mathrm{D}\end{array}$ & $\begin{array}{c}0.50 \pm 0.01 \\
\mathrm{C}\end{array}$ & $\begin{array}{c}0.11 \pm 0.01 \\
\mathrm{D}\end{array}$ & 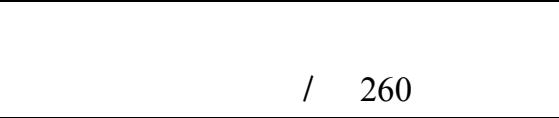 & 2 \\
\hline $\begin{array}{c}1.86 \pm 0.05 \\
\mathrm{~A}\end{array}$ & $\begin{array}{c}11.11 \pm 0.04 \\
\mathrm{~A}\end{array}$ & $\begin{array}{c}0.71 \pm 0.03 \\
\mathrm{~A}\end{array}$ & $\begin{array}{c}1.59 \pm 0.34 \\
\mathrm{~A}\end{array}$ & بجرعة 100 ملغم/كغم وزن جهم وعليقة قيلسية & 3 \\
\hline $\begin{array}{c}1.11 \pm 0.11 \\
\mathrm{~B}\end{array}$ & $\begin{array}{c}10.49 \pm 0.03 \\
\mathrm{~B}\end{array}$ & $\begin{array}{c}0.60 \pm 0.03 \\
\mathrm{~B}\end{array}$ & $\begin{array}{c}1.09 \pm 0.05 \\
\text { B }\end{array}$ & 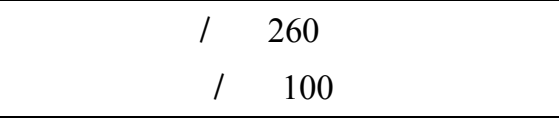 & 4 \\
\hline
\end{tabular}

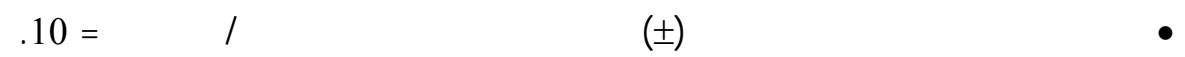

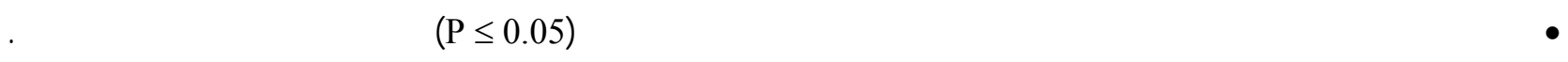

يبين الجدول (1) حدوث انخفاض معنوي (P<0.05) في مستوى هرمون الثايروكسين T4 ف مي مه صل

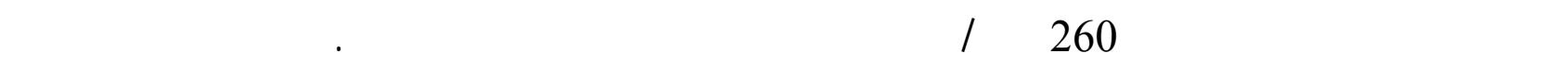

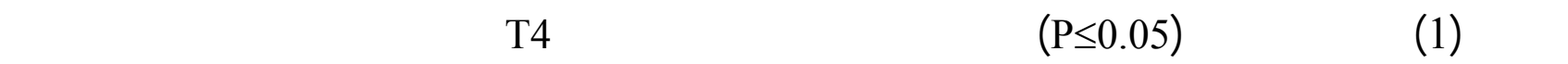

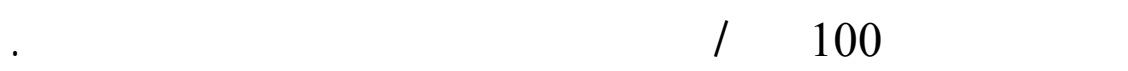

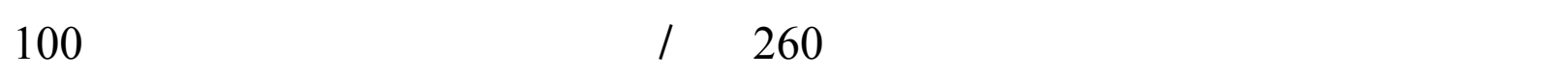

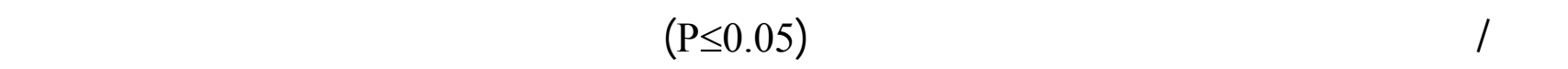

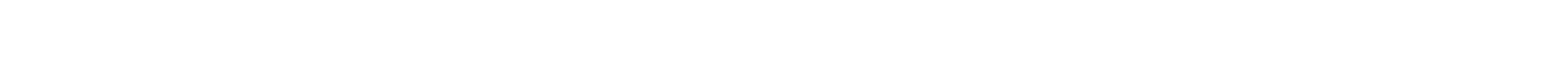
اللسطرة.

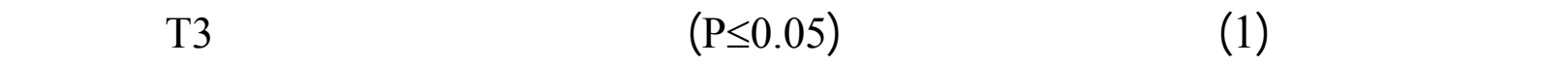

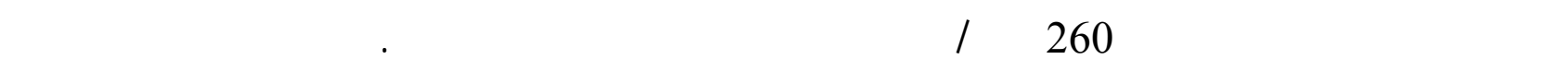

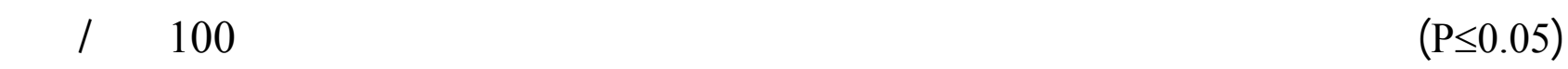
وزن جهم مقارنة مع مجموعة اللسيطرة.

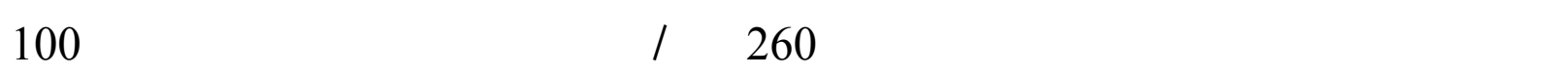

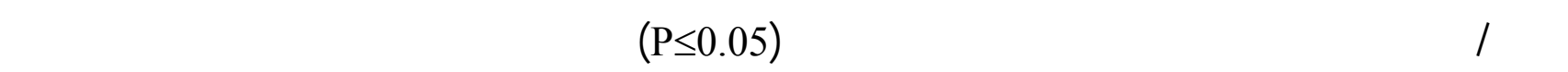

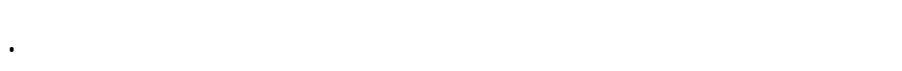

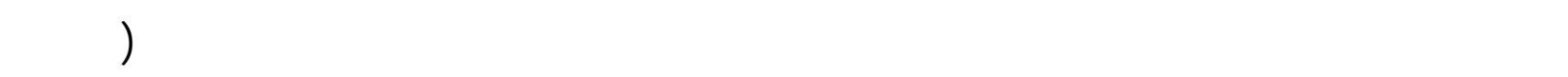

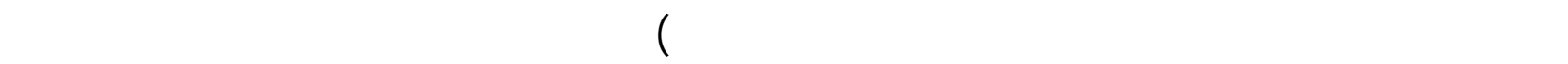




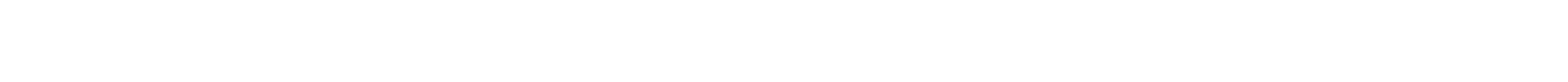

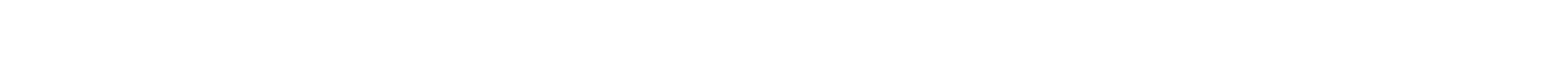

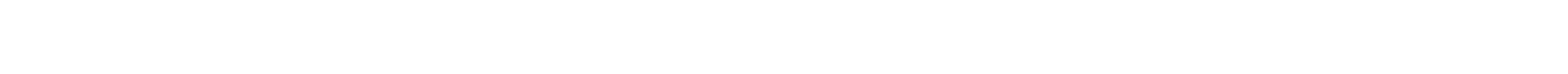

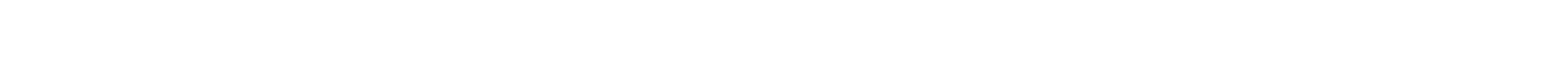

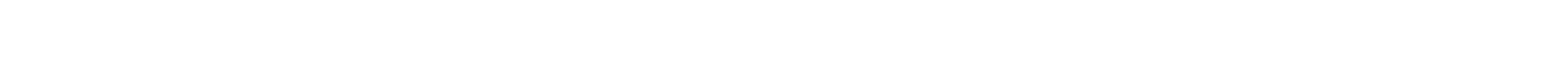

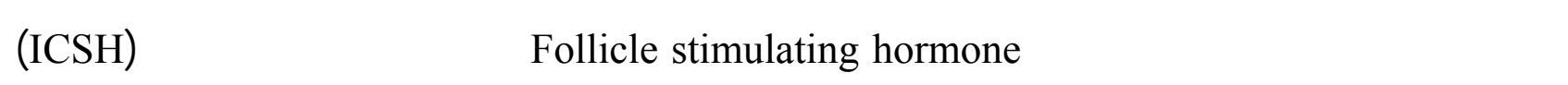
Interstitial Cell Stimulating Hormone البينية (Sturkie, 1986) لذا فإن انغخاض مستوى هرمون Follicle stimulating hormone تكوين هرمون التستوستيرون الذكري من خلايا ليدك لان الدور الذي يلعبه الهرمون المحفز للخلايا الخلالية

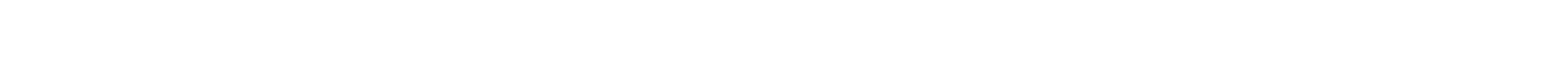

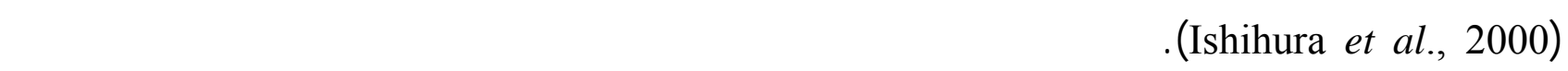

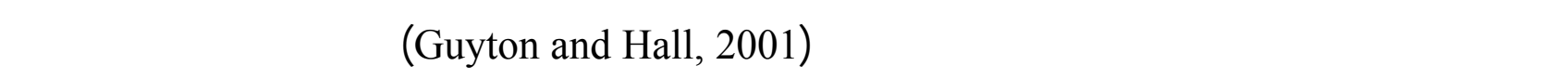

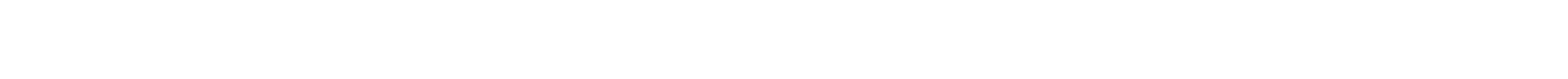

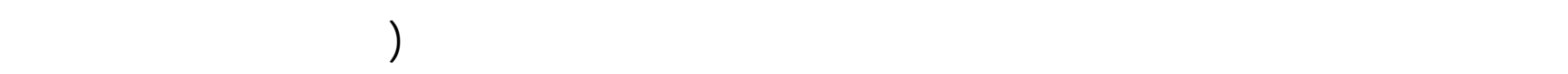

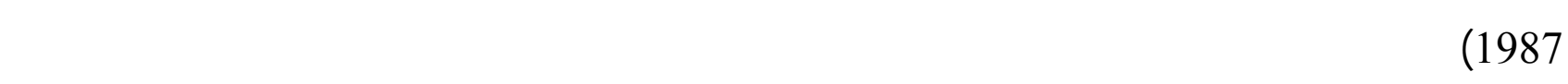

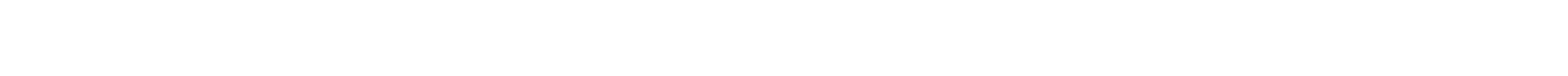
الكثافة والكولسترول (Ganong, 2003).

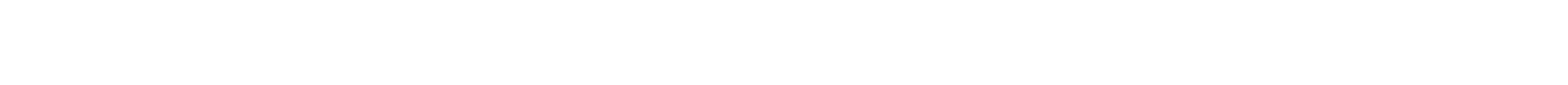

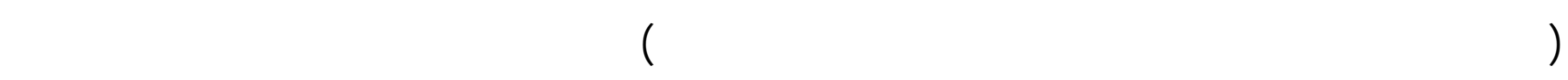

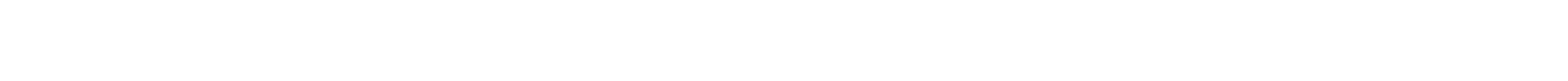

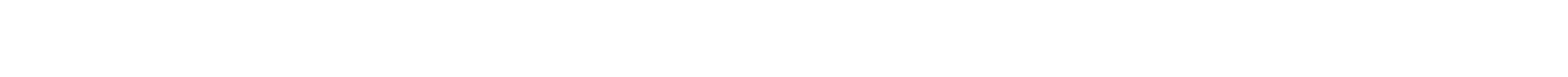

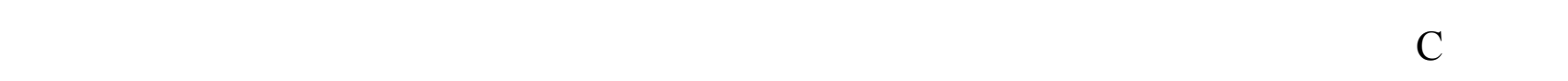

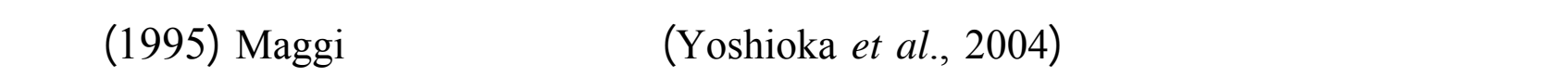

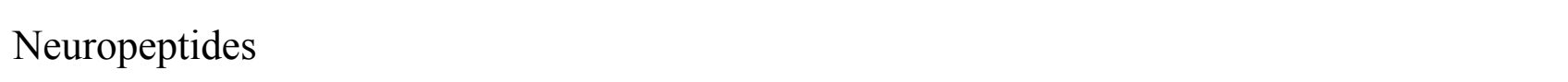

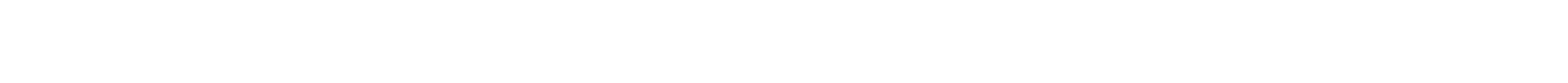
المتخصص لمركب الكبسلسن وهو

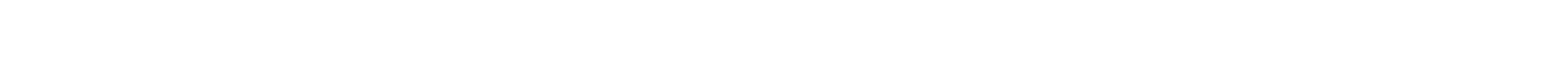

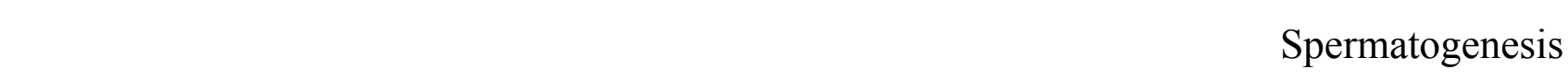
الكبسلسين (Fausson et al., 2005)، كما أن وجود فيتلمين البايوتين وبعض الفيتلمينت الأخرى في الفلف لـ لـ الفيل 
الأحمر مثلاً (E, C, A) ومادة الكبسلسن الفعالة اللاذعة يع ـدمحف _زأ للغ ـة النخلمي ـة لإف ـراز هرمه -ون الثايروتروبين ومحفزَ للدرقية على إفراز الثايروكسينوالثايرونين (Oboh et al., 2007).

\section{تأثير الكولسترط والفالل الأحمرفي أوزلن نكور الأرلب المحلية بعد أرسمة وثمانية أس لببع م ن بـ دs}

المعاملة

أوضحت النتائج في الجدول (2) حدوث زيادة في أوزان الأرلغب المعلملة بالكولسترول 260 ملغم الكغم

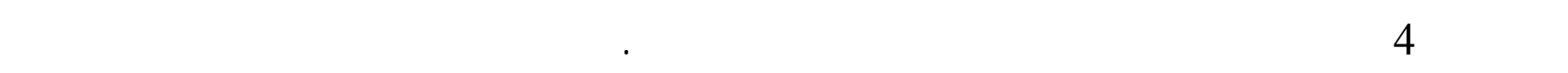

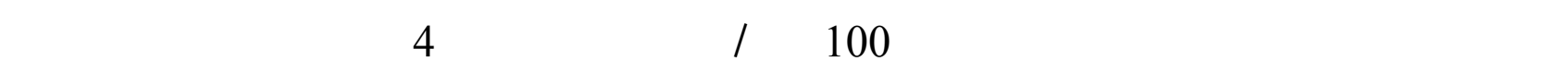

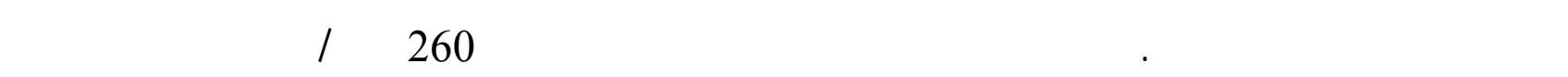

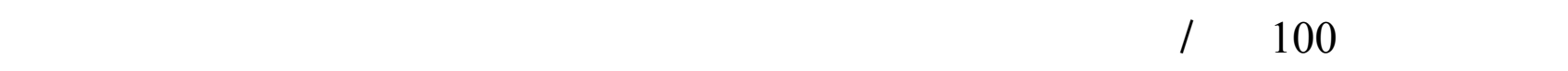

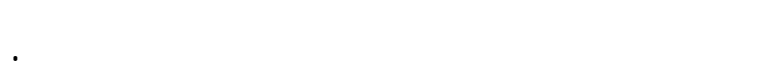

الجطل 2: تأثير الكولسترط والفلل الأحمرفي أوزل نكور الأرلب المحلية به دمه ـور 4 و8 ألس البع على المعاملة.

\begin{tabular}{|c|c|c|c|}
\hline الونن بهد 8 أسلبع & الوزن بهد 4 أسلبيع & المعاملات & المجامع \\
\hline $1383 \pm 92.3$ & $1308 \pm 87.3$ & 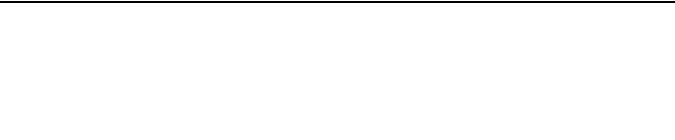 & 1 \\
\hline $1416 \pm 88.62$ & $1331 \pm 91.84$ & بتركيز 260 ملغم/كغم عليقة وماء مقطرر & 2 \\
\hline $1054 \pm 83.6$ & $1131 \pm 86.7$ & بجربة 100 ملغم الكغم وزن جهم وعليقة قيلسية & 3 \\
\hline $1196 \pm 59$ & $1214 \pm 88.5$ & الكوليسترول بتركيز 260 ملغم/كغم عليقة والففل 100 ملغم الكغم وزن جهم بجمر & 4 \\
\hline
\end{tabular}

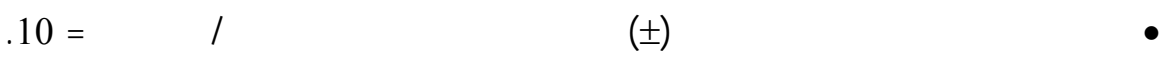
• • • •

أوضحت النتائج في الجدول (2) حدوث زياة في أوزان الأرانب المحلية المعلملة بالكول سترول 260

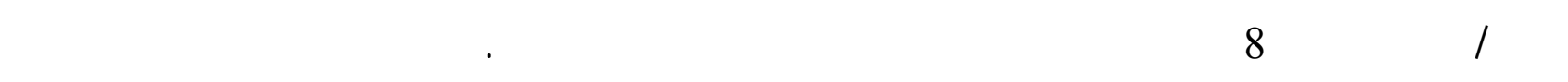

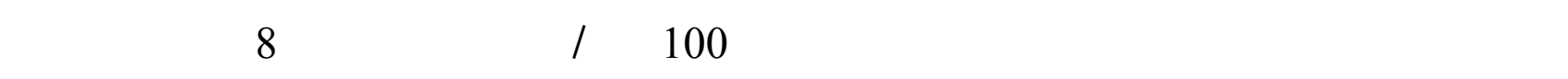


المعلملة مقارنة مع مجموعة للسطرة. وبينت النتائج أن معلملة الأرانب بالكولسترول 260 ملغم/كغم عليقة

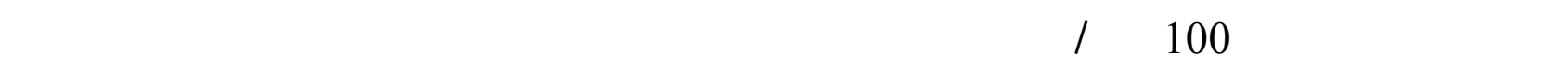

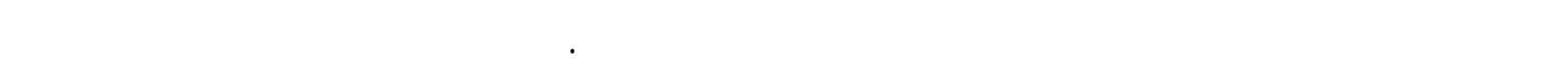

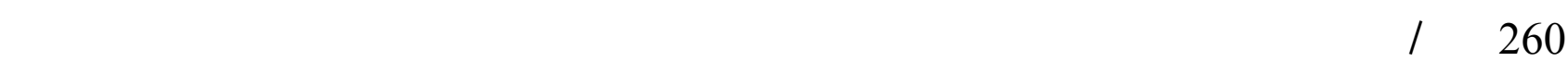
النتيجة مع ما توصل إليه الجبوري (2009) عندمعلملته للجرذان المتغنية على عليقة حاوية على كولسترول

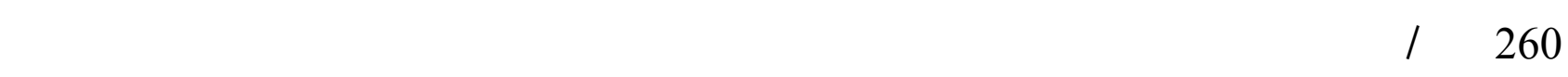

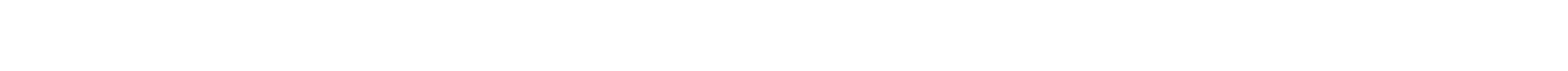
وخاصة حول الكلى وبالتالي زيادة الوزن. وأدت المعلملة بالفالف الأحمر إلى حدوث النخفاض معنوي في أوزان الأرافب المعلملة وهذه النتيجة تجفق

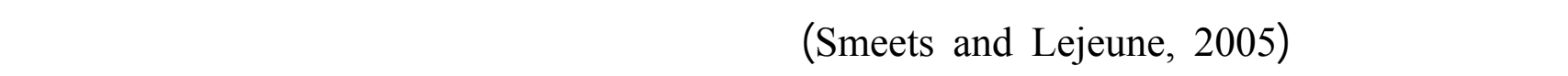

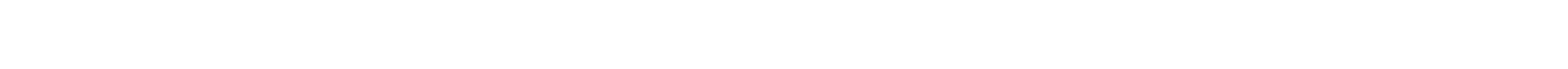

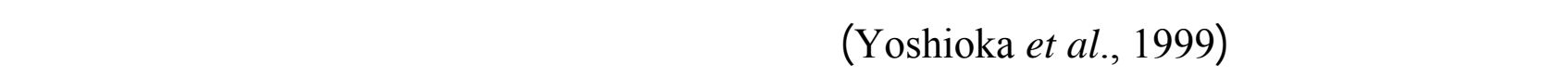

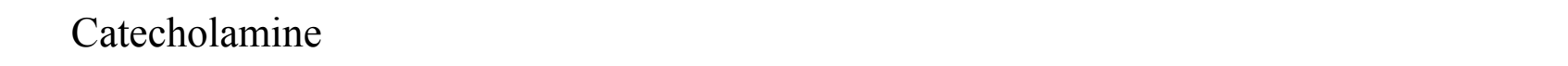
لب الغة الادرينالية وزيادة حرق المواد الكاربوهيدراتية والدهون.

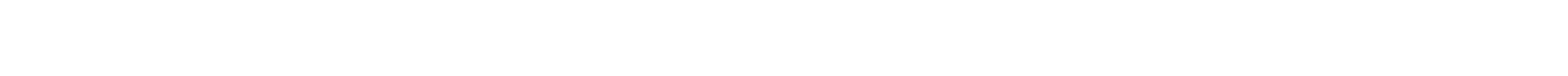

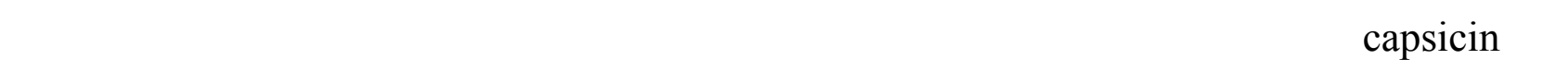
إفراز هرمونات الكلسترين المعدي والمعوي وإفراز الهرمونات التي لها علاقة بالهضم وجمبع هذه التأثيرات

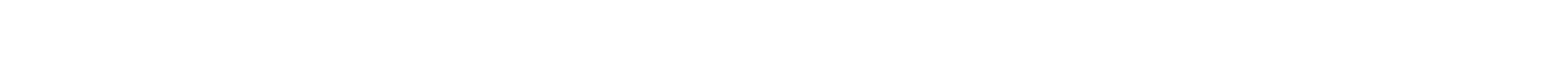

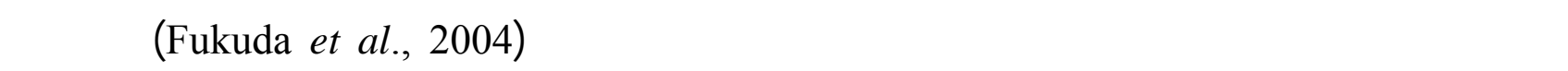

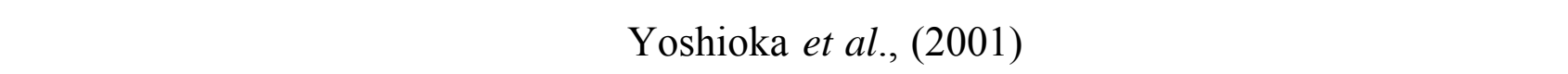

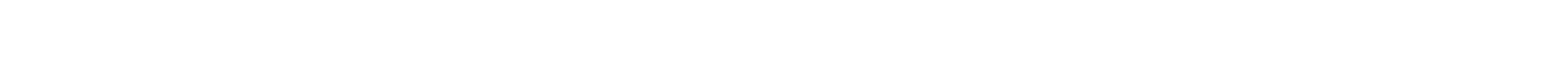

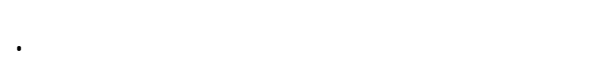

\section{الستنتلجك}

ان ملحققته الدرلسة الحالية من نتائج ققود اله لستنتلجك يمكن اليجازها فيما يأتي:

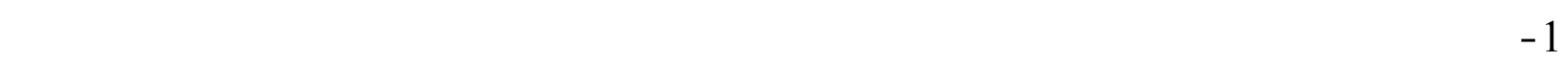

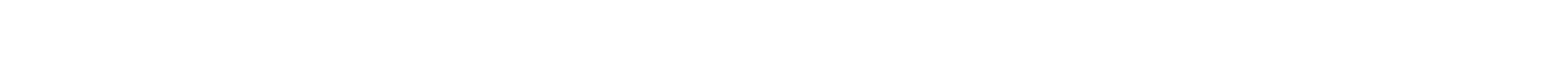
الثايرونين. 2 - عمل الفلفل الأحمر على خفض أوزان نكور الأرافب المعلملة به مقارنة مع جقية المجلمبع المعلملة. 


\section{المصار العرسة}

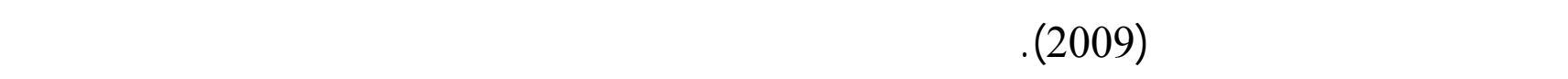

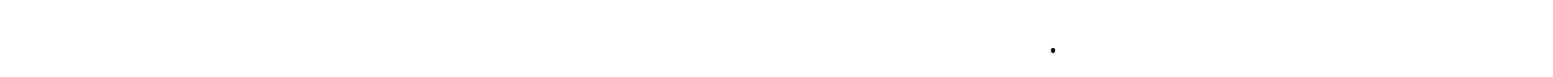

العراق.

الخولجة، علي كلظم ؛ البياتي، الهلم عبداه ؛متي،سمير عبد الأحد (1978). التركيب الكيمي اوي والقيم ـة

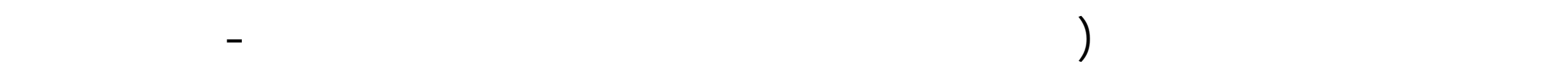
العراقية).

عنتر،سالم حمادي (2010). التحللي الإحصائي في البهث العلم مي وبرن لمج SAS. دار الكت ب الطباء ـة والنشر، جلمعة الموصل، العراق.

مجي الين، خير البن ؛ يوسف، وليد حميد (1987). علم الفسلجة البيطرية. وزارة التعليم الع الي والبح ثاث

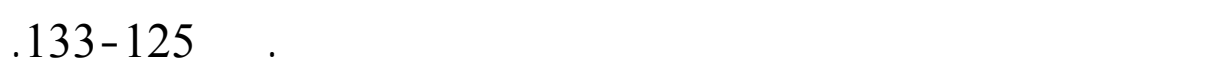
المصادر الأجنبية

Agrawal, R.C.; Bhide, S.V. (1987). Biological studies on carcinogencity of chillies in Balb/c mice tests. Indian J. Med. Res., 86, 391-396.

Ahuja, K.D.; Robertson, I.K.; Geraghry, D.P.; Ball, M.J. (2006). Effect of chili consumption on postprandial glucose, insulin and energy metabolism. Am. J. Clin. Nutr., 84, 639.

Ameli, S.; Hultge A. ; Nilsson, T. (1996). Effect of immunization with homologous LDL and oxidized LDL on early atherosclerosis in hypercholesterolemia. Athero. Thromb. Vas. Bio. 16 k, 1074-1088.

Batchelor, G.R. ; Giddins, G. (1995). Body weight changes in laboratory rabbits subjected to transport and different housing conditions. Anim. Technol. (Soussex): The Institute Ang., 46(2), 89-95.

Cheij, R. (1984). "McDonald Encyclopedia of medical plant. McDonald and Co". (publishers). Ltd. London, pp. 209, 309, 313.

DeBeljuk, L.; Roa, J.N.; Bartke, A. (2003). Tachykinins and their possible modulatory role on testicular function: a review. Ind. J. Androl., 26, 202-210.

Erdost, H.; Ozfiliz, N.; Ozguden, C; Gunes, N.; Onen, S.; Ilhan, T.; Ozer, A. (2007). Expression of a capsaicin receptor (VR1) in the tests of mice after an application of capsaicin. Bull. Net. Inst. Pulawy., 51, 649-653.

Fausson, M.S.; Taddi, A.; Bizzoco, E.; Lazzeri, M.; Vannucchi, M.G.; Bechi, P. (2005). Distribution of the vanilloid (Capsaicin) receptor type 1 in the human stomach. Histochem Cell Biol, 124, 61-68.

Flomenbaum, N.E.; Goldfrank, L.R.; Hoffman, R.S.; Howland, M.A.; Lewon, N.A.; Nelson, L.S. (2006). "Golldfranks Toxicologic". Emergencies. 8th edn., McGraw-Hill, New York.

Fukuda, H.; Mizuta, Y.; Isomoto, H.; Takeshima, F.; Ohnita, K.; Ohba, K.; Omagari, K.; Taniyama, K. ; Koneno, S. (2004). Ghrelin enhances gastric motility through direct 
stimulation of intrinsic neural pathways and capsaicin-sensitive afferent neurons in rats. Scand. J. Gastro. 39,1209-1214.

Ganong, W.F. (2003). "Review of Medical Physiology". McGraw-Hill Companies, New York, pp. 310-311.

Guyton, A.C.; Hall, J.E. (2001). "Text Book of Medical Physiology". W.B. Saunders Company, Philadelphia, 789p.

Ishihura, M.; Itoh, M.; Miyamoto, K.; Suna, S.; Takenchi, Y.; Takenaka, I.; Jitsunar, F. (2000).Spermatogenic disturbance induced by Di(2-Ethylhexyl) phthalate is significantly prevented by treatment antioxidant vitamins in the rat. It. J. Androl., 23, 85-94.

Kawabata, F.; Inoue, N.; Yazawa, S.; Kawada, T.; Inoue, K.; Fushiki, T. (2006). Effect of CH-19 sweet, a non-pungent cultivar of red pepper, in decreasing the body weight and suppressing body fat accumulation by sympathetic nerve activation in humans. Bios. Biotechnol. Biochem.,70, 2824-2835.

Kendabie, K.O. ; Adjene, J.O. (2007). Histological studies of the effects of red pepper on the stomach of adult wistar rats. Rev. Electron Biomed Electron J. Biomed., 3, 1317.

MacGvillivary, J.H. (1961). "Vegetable production". McGraw-Hill Book Comp. Inc. (edc.), New York, (1), 397p.

Maggi, C.A. (1995). The Mammalian Tachykinin receptors. Gen Pharmacol. 26, 911-944.

Mathur, R.; Dangi, R.S.; Dass, S.C.; Malhotta, R.C. (2000). The hot test chili variety in India. Curr. Sci., 79(3), 287-288.

National Research Council.(1994). "Nutrient Requirement of Poultry". 9th edn. Revised national academy press, Washington D.C.

Oboh, G.; Puntelb, R.L. ; Rochab, J.B.T. (2007).Hot pepper (Capsicum annuum, Tepin and Capsicum Chinese, Habanero). Prevents $\mathrm{Fe}^{+2}$ induced lipid peroxidation in brain in vitro. Food Chem., 102(1), 178-185.

Pandit, N.N.; Singh, J. ; BhattaCharjee, D.K. (1979). Impact of Feeding Chakwar (Casiatora) Seed on the growth of broilers. Indian J. Poult. Sci., 14, 176.

Smeets, A. ; Lejeune, M.P. (2005). Sensory and gastriontestinal satiety effects of Capsaicin on food intake. Int. J. Obes (Lond) 29, 682-688.

Smeets, A.J. ; Margriet, S. (2009). The acute effects of a lunch containing Capsaicin on energy and substrate utilization, hormones, and satiety. Eur J. Nutr., 48, 229-234.

Sturkie, P.D. (1986). "Aviam Physiology". 4th edn. Springer Verlag. New York, 271p.

Yoshioka, M.; Pierre, S.; Drapeau, V.; Dionne, I.; Doucet, E.; Suzuki, M.; Tremblay, A. (1999). Effect of red pepper on appetite and energy intake. Br. J. Nutr., 82, 115 123.

Yoshioka, M.; Doucet, E. Drapeau, V.; Dionne, I.; Tremblaly, A. (2001). Combined effect of red pepper and caffeine consumption on $24 \mathrm{~h}$ energy balance in subjects given free access to foods. Br. J. Nutr., 85, 203-211.

Yoshioka, M.; Imanag, M.; Ueyama, H. (2004). Maximum tolerable dose of red pepper decreases fat intake independently of spicy sensation in the mouth. Br. J. Nutr., 91, 991-5. 